\title{
Optical Coherence Tomography as a Diagnostic Tool of Ischemic Macular Edema of Diabetic Retinopathy
}

\author{
AMIRA M. HAZAA, M.B.B.Ch.; ABDELRHMAN G. SALMAN, M.D.; REHAM F. ELSHINAWY, M.D. and \\ WAEL A. GOMAA, M.D.
}

The Department of Ophthalmology, Faculty of Medicine, Ain Shams University

\begin{abstract}
Background: Diabetic Macular Ischemia (DMI) is recognized as an important cause of visual disability, it is considered as an important clinical feature of Diabetic Retinopathy (DR). Disorganization of Retinal Inner Layer (DRIL) is defined as the horizontal extent in microns for which any boundaries between the ganglion cell-inner plexiform layer complex, inner nuclear layer, and outer plexiform layer could not be identified.and considerd as featurer of capillary non perfusion.

Aim of Study: To study the rule of dril assessed by Optical Coherence Tomography (OCT) in differentiation between the ischemic and non-ischemic diabetic maculopathy.

Patients and Methods: 66 eyes of 66 patients were enrolled in prospective study and divided into 3 equal subgroups; control normal patients, patients with ischemic diabetic maculopathy and patients with non-ischemic diabetic maculopathy diagnosed by FFA. All patients underwent full ophthalmological examination and OCT macula was done to assess the DRIL.
\end{abstract}

Results: We found that there was highly statistically significant difference $(p=0.000)$ between non ischemic and ischemic groups as regard presence or absence of DRIL.

Sensitivity of DRIL (by OCT) is $86.36 \%$, specificity is $81.82 \%$, positive predictive value is $82.61 \%$ and negative predictive value is $85.71 \%$.

Conclusion: There was a statistically significant difference in presence or absence of DRIL between ischemic and nonischemic diabetic retinopathy.

Key Words: Diabetic maculopathy-DRIL-OCT.

\section{Introduction}

DIABETIC retinopathy is a major complication in diabetic patients and considered as the principle cause of visual disability in the working age group in developed countries [1].

Disorganization of Retinal Inner Layer (DRIL) is defined as the horizontal extent in microns for

Correspondence to: Dr. Amira M. Hazaa, The Department of Ophthalmology, Faculty of Medicine, Ain Shams University which any boundaries between the ganglion cellinner plexiform layer complex, inner nuclear layer, and outer plexiform layer could not be identified [2]. DRIL affecting 50\% or more of the central 1$\mathrm{mm}$-widezone centered on the fovea (foveal DRIL) is associated with worse VA [3]. The finding of DRIL is assessed independently and is not graded differently in the presence of retinal edema ,intra retinal cysts, or any other SD-OCT-evident pathology [2]

\section{Aim of study:}

To detect if DRIL assessed by macular OCT can differentiate between ischemic and nonischemic diabetic maculopathy.

\section{Patients and Methods}

A prospective study was carried on 66 eyes of 66 diabetic patients, with age ranged between 30 50 years; divided into 3 equal subgroups; control group, diabetic ischemic and diabetic non-ischemic maculopathy diagnosed by FFA. The study was done on Ain Shams University Hospital outpatients from September, 2018 till August, 2019.

We included all patients with diabetic ischemic maculopathy diagnosed with FAA graded by using standard photographs from ETDRS Briefly, patients were given a score of absent (no disruption of the FAZ), questionable (outline is not smooth or oval, but changes are not clearly pathologic), mild (outline of the FAZ is destroyed for less than half the original circumference), moderate (outline of the FAZ is destroyed for greater than half the original circumference), severe (outline of the FAZ is completely destroyed).

We excluded all patients with pathological conditions may affect the retina such as high myopia, Glaucoma, ocular trauma and artery occlusion. 
The protocol of this study was approved by the Medical and Ethical Committee of Ain Shams University. The patients were informed about the procedure and written consent was obtained.

All the patients underwent complete ophthalmological examination including best corrected visual acuity, complete anterior segment examination using slit-lamp bio-microscopy, as well as IOP measurement using Goldmannapplanation tonometer and posterior segment examination using Volk lens +90D. FFA and Macular OCT using OCT RS-3000 NIDEK.

\section{Results}

The current prospective study was carried on 66 eyes from 66 patients, with age ranged between $30-50$ years.

1- The logmar wase not normally distributed the most apprppriate statistically test was Mannwhitneyu test. (Value of logmar was statistically significant difference) (Table 1).

Mann-whitney test was used to compare age and $\log$ mar, between 3 groups control, non ischemic and ischemic.

Table (1): Comparison between the three groups regarding the studied groups.

\begin{tabular}{|c|c|c|c|c|c|c|c|c|c|c|c|c|c|c|}
\hline & \multicolumn{3}{|c|}{ Control } & \multicolumn{3}{|c|}{ Non Ischemic } & \multicolumn{3}{|c|}{ Ischemic } & \multicolumn{2}{|c|}{$\begin{array}{c}\text { Kruskal-Wallis } \\
\text { Test }\end{array}$} & \multicolumn{3}{|c|}{ Mann-Whitney Test } \\
\hline & Median & $\begin{array}{l}\text { Perc. } \\
25\end{array}$ & $\begin{array}{l}\text { Perc. } \\
75\end{array}$ & Median & Perc. & $\begin{array}{l}\text { Perc. } \\
75\end{array}$ & Median & $\begin{array}{c}\text { Perc. } \\
25\end{array}$ & $\begin{array}{l}\text { Perc. } \\
75\end{array}$ & $x^{2}$ & $p$-value & $C \& N$ & $C \& I$ & N \& I \\
\hline Age & 45.00 & 40.00 & 49.00 & 49.00 & 47.00 & 50.00 & 48.00 & 45.00 & 50.00 & 8.497 & $0.014^{*}$ & $0.008 *$ & $0.027 *$ & 0.369 \\
\hline Log mar & 0.00 & 0.00 & 0.00 & 0.17 & 0.17 & 0.30 & 0.30 & 0.17 & 0.47 & 40.286 & $<0.001 *$ & $<0.001 *$ & $<0.001 *$ & $0.046^{*}$ \\
\hline
\end{tabular}

2- We compare OCT of non ischemic and ischemic groups as regard presence or absence of Dril $4 / 22$ patients of non ischemic group had Dril while 19/22 patients of ischemic group had Dril, we faund that there was highly statistically significant difference $(p 0.000)$ (Table 3$)$.

Table (2): Comparison between non ischemic and ischemic groupsin presence of dril or not by OCT.

\begin{tabular}{lccc}
\hline & Non Ischemic & Ischemic & $p$-value \\
\hline No drill: & & & 0.000 \\
Count & 18 & 3 & \\
\% within OCT & $85.7 \%$ & $14.3 \%$ & \\
\% within group & $81.8 \%$ & $13.6 \%$ & \\
Drill: & & & \\
Count & 4 & 19 & \\
\% within OCT & $17.4 \%$ & $82.6 \%$ & \\
\% within group & $18.2 \%$ & $86.4 \%$ & \\
\hline
\end{tabular}

Table (3): Evaluate the sensitivity, specificity of DRIL by OCT and positive and negative predictive values of DRIL in the diagnosis of ischemic maculopathy.

\begin{tabular}{lll}
\hline - Sensitivity (\%) (95\% CI) & $86.36 \%$ & $65.09 \%$ to $97.09 \%$ \\
- Specificity (\%) (95\% CI) & $81.82 \%$ & $59.72 \%$ to $94.81 \%$ \\
- Predictive value of & $82.61 \%(*)$ & $65.84 \%$ to $92.13 \%$ \\
positive (\%) (95\% CI) & & \\
- Predictive value of & $85.71 \%(*)$ & $67.30 \%$ to $94.59 \%$ \\
negative (\%) (95\% CI) & & \\
- Accuracy (\%) (95\% CI) & $84.09 \%(*)$ & $69.93 \%$ to $93.36 \%$ \\
\hline
\end{tabular}

Sensitivity of dril (by OCT) is $86.36 \%$, specificity is $81.82 \%$, positive predictive value is $82.61 \%$ and negative predictive value is $85.71 \%$.

\section{Case from group 2:}

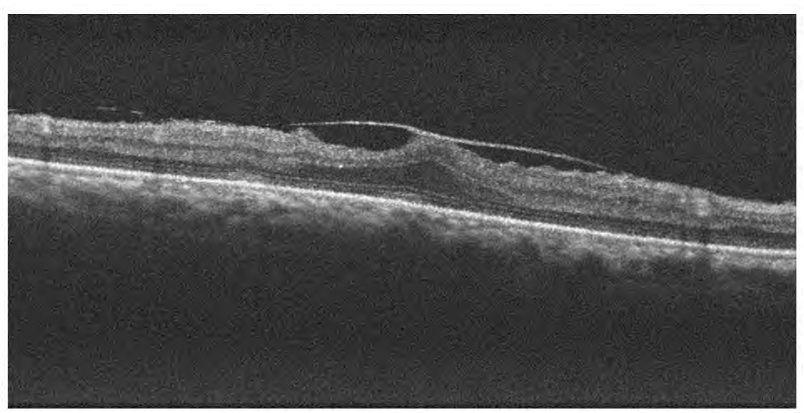

Fig. (1): OCT of diabetic ischemic maculopathy patient and precense of dril.

Case from group 2:

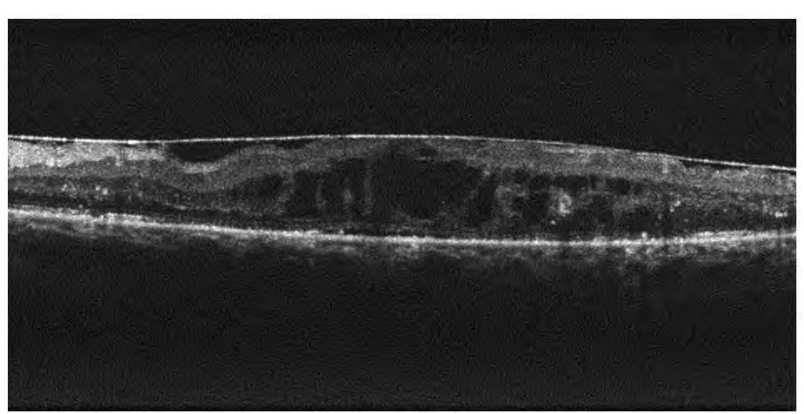

Fig. (2): OCT of diabetic ischemic maculopathy patient and precense of dril. 
Case from group 3:

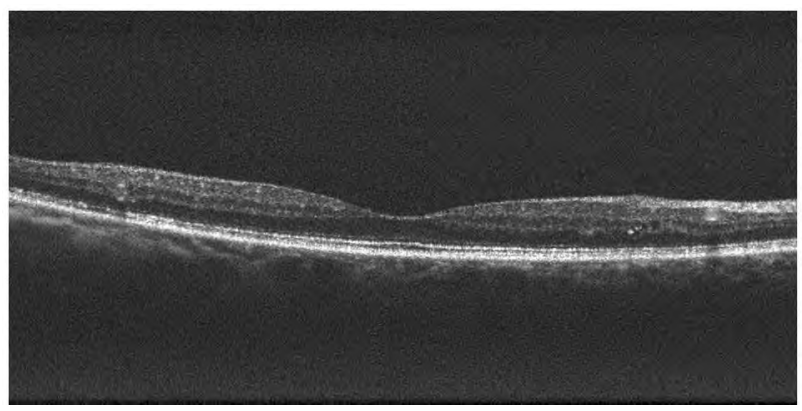

Fig. (3): OCT of diabetic non ischemic maculopathypatient without dril.

\section{Discussion}

Diabetic Retinopathy (DR) is advanced microvascular disorder that is considered the commonest leading reason of acquired vision loss in adults crosswise the globe. The World Health Organization (WHO) estimates that the total number of adults with diabetes mellitus will reach 366 million by 2030 and the number of people with DR will reach 191 million by 2030 [4].

OCT is a rapid, non-invasive imaging modality that uses light waves to render across sectional view of the retina in vivo. It creates high resolution images of retinal morphology allowing volumetric quantification of retinal and choroidal thickness and macular edema. OCT allows clinicians to distinguish macular edema in patients before retinal thickening is visible on slit lamp microscopy [5]

DRIL is an OCT resultant biomarker that has been revealed to be of a value in prediction of base line VA and that after resolution of diabetic macular edema [6].

In the present study BCVA was significantly decreased in diabetic patients than controls and in patients with ischemic maculopathy than diabetic patients without maculopathy. Raja and his colleagues found that the majority of our patients were presenting in the range of 6/24-6/36 (Raja et al., 2017) [7].

In the present study logmar was significantly increased among the ischemic maculopathy group. The association between macular ischaemia and poor visual acuity is known (Lee et al., 2013) [8]

In the present study age was significantly increased in DRIL group than non-DRIL group. In accordance with our findings Joltikov and his colleagues found that; longer diabetes duration in persons with DRIL (Joltikov et al., 2018) [9].
Disorganization of the inner retinal layers (DRIL) is an OCT-derived biomarker that has been shown to be predictive of baseline VA as well as the VA after resolution of macular edema in both diabetes and uveitis (Grewal et al., 2017) [6] and (Sun et al., 2014) [3]. Sun and his colleagues showed that the presence of foveal DRIL was associated with worse baseline visual acuity in patients with Diabetic Macular Edema (DME) (Sun et al., 2014) [3]

DRIL was associated with nonperfusion and thus foveal DRIL may in fact be related to an enlarged foveal avascular zone or macular ischaemia. Notably, DRIL was the only OCT feature that was associated with worse VA at final follow-up (Nicholson et al., 2015) [10]

In the present study, on applying ROC curve to assess the diagnostic accuracy of DRIL, we found that DRIL has sensitivity of $86.36 \%$, specificity of $81.82 \%$, positive predictive value of $82.61 \%$, negative predictive value of $85.71 \%$ and accuracy of $84.09 \%$. Nicholson and his colleagues found that DRIL can be used to detect macular CNP in patients with diabetic retinopathy. The diagnostic sensitivity was $84.4 \%$ and specificity was $100 \%$. From a clinical perspective, the presence of DRIL is a very useful alternative to performing FA to identify CNP as DRIL is a definite indicator of nonperfused retina. There were no false positives. However, it is useful to consider the clinical implications of absence of DRIL in the presence of angiographic evidence of CNP (false negatives). With regard to false negatives, $7 / 45(25.6 \%)$ angiographic evidence of CNP did not manifest as DRIL. Therefore, the absence of DRIL does not rule out CNP. This may suggest that the disorganization of retinal layers may only occur after a period of CNP or it is a sequelae of CNP. (Nicholson et al., 2015) [10]

\section{Conclusion:}

Our study we can differentiate between ischemic and non ischemic diabetic maculopathy by presence or absence of Disorganization of Retinal Inner Layer (DRIL), assessed by OCT.

Macular ischemia and an enlarged foveal avascular zone may contribute to foveal DRIL and reduced visual acuity.

\section{References}

1- CONGDON N.G., FRIEDMAN D.S. and LIETMAN T. Important causes of visual impairment in the world today. JAMA, 2057-2060 (15): 290, 2003. 
2- SUN J.K., LIN M.M., LAMMER J., PRAGER S. SARANGI R., SILVA P.S. and AIELLO L.P.: Disorganization of the retinal inner layers as a predictor of visual acuity in eyes with center-involved diabetic macular edema. JAMA Ophthalmology, 132 (11): 1309-16, 2014.

3- SOLIMAN A.Z., RADWAN S.H. and PRAGER S.G. Spectral domain optical coherence tomographyparameters associated with visual acuity in patientswith resolved center-involved diabetic macularedema. Invest. Ophthalmol. Vis. Sci., ARVO E-Abstract 1338, 2012.

4- TING D.S.W., CHEUNG G.C.M. and WONG T.Y.: Diabetic retinopathy: Global prevalence, major risk factors, screening practices and public health challenges: A review. Clin. Exp. Ophthalmol., 44 (4): 260-77, 2016.

5- LEE J. and ROSEN R.: Optical coherence tomography angiography in diabetes. Curr. Diab. Rep., 16 (12): 123 , 2016.

6- GREWAL D.S., O'SULLIVAN M.L., KRON M. and JAFFE G.J.: Association of Disorganization of Retinal Inner Layers With Visual Acuity In Eyes With Uveitic Cystoid Macular Edema. Am. J. Ophthalmol., 177: 11625, 2017.
7- RAJA A.M., SEEMA G. and PRASAD R.: Diabetic Maculopathy in Nonproliferative Diabetic Retinopathy in Tertiary Eye Care Hospital in India: A Prospective Nonrandomized Clinical Study. Int. J. Sci. Stud., 5 (5): 144-9, 2017.

8- LEE D.H., KIM J.T., JUNG D.W., JOE S.G. and YOON Y.H.: The relationship between foveal ischemia and spectraldomain optical coherence tomography findings in ischemic diabetic macular edema. Invest. Ophthalmol Vis. Sci., 54: 1080-5, 2013.

9- JOLTIKOV K.A., SESI C.A., De CASTRO V.M., DAVILA J.R., ANAND R., KHAN S.M., FARBMAN N., JACKSON G.R., JOHNSON C.A. and GARDNER T.W.: Disorganization of Retinal Inner Layers (DRIL) and Neuroretinal Dysfunction in Early Diabetic Retinopathy. Invest. Ophthalmol. Vis. Sci., Nov. 1, 59 (13): 5481-6. doi: 10.1167/iovs.18-24955, 2018.

10- NICHOLSON L., RAMU J., TRIANTAFYLLOPOULOU I., PATRAO N.V., COMYN O., HYKIN P. and SIVAPRASAD S.: Diagnostic accuracy of disorganization of the retinal inner layers in detecting macular capillary non-perfusion in diabetic retinopathy. Clinical and Experimental Ophthalmology, 43: 735-41, 2015.

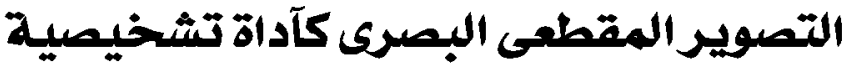

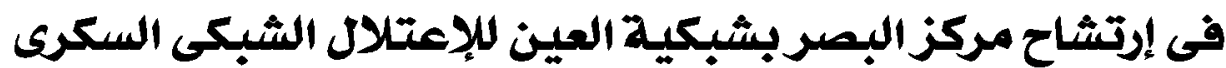

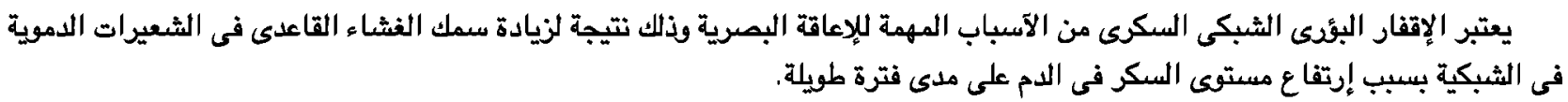

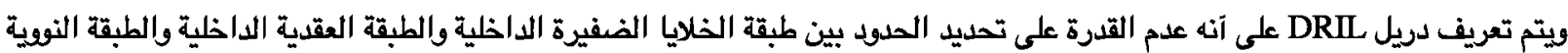
الداخلية والطبقة الضفيرة الخارجية. ويؤثر دريل DRIL على • \% أو آكثر من المنطقة المركزية وهذا يؤدى إلى تآثر حدة الإبصار.

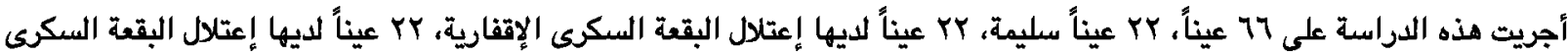

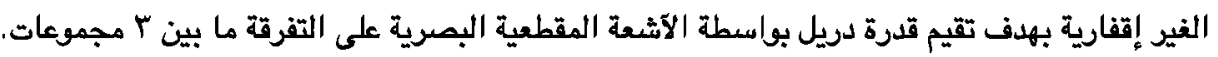

يتراوح عمر المرضى فى هذه الدراسة من • ب إلى +0 عام، تم آخذ تاريخ مرضى وجراحى ولدوائى لجميع المرضى وتم فحصهم كاملاً قبل إجراء الآشعة المقطعية البصرية على العين.

وقد ثبت طبقاً لدراستنا الصالية آن الدريل إستطاع التفرتة بين الحالات التى لديها إعتلال البقعة السكرى الإقفارية والحالات التى لديها إعتلال البقعة السكرى الغير إقفارية، بينما لم يستطيع الدريل التفريق بين حالات الوضسع الطبيعى وحالات إعتالل البقعة السكرى الغير إقفارية. 